\title{
Treatment aspirations and attitudes towards innovative medications among people living with HIV in 25 countries
}

\begin{abstract}
Patricia de los Rios ${ }^{1}$, Chinyere Okoli ${ }^{2}$, Benjamin Young ${ }^{1}$, Brent Allan $^{3}$, Erika Castellanos ${ }^{4}$, Garry Brough ${ }^{5}$, Anton Eremin 6 ,
\end{abstract} Giulio M. Corbelli ${ }^{7}$, W. David Hardy ${ }^{8}$, Nicolas Van de Velde ${ }^{2}$

\author{
AFFILIATION \\ 1 ViiV Healthcare, Research Triangle Park, United States \\ 2 ViiV Healthcare, Brentford Middlesex, United Kingdom \\ 3 International Council of AIDS Service Organizations (ICASO), Toronto, \\ Canada \\ 4 Global Action for Trans* Equality (GATE) \\ 5 Positively UK, London, United Kingdom \\ 6 AIDS Center Foundation, Moscow, Russia \\ 7 European AIDS Treatment Group, Rome, Italy \\ 8 Division of Infectious Diseases, Johns Hopkins University School of \\ Medicine, Johns Hopkins University, Baltimore, United States
}

Popul. Med. 2020;2(July):23

\section{CORRESPONDENCE TO}

Patricia de los Rios. ViiV Healthcare, Research Triangle Park, North Carolina, 27709, United States.

E-mail: patricia.x.delosrios@viivhealthcare.com

\section{KEYWORDS}

quality of life, stigma, treatment adherence, co-morbidities

Received: 9 May 2020, Revised: 28 June 2020,

Accepted: 29 June 2020

https://doi.org/10.18332/popmed/124781

\begin{abstract}
INTRODUCTION The worldview in relation to patient care has shifted from conquering diseases to improving overall wellbeing and quality of life. We examined treatment aspirations among people living with HIV (PLHIV).

METHODS In all, 2389 PLHIV were surveyed in the 25-country 2019 Positive Perspectives Study. Descriptive and multivariable analyses were used to explore attitudes towards treatment.

RESULTS Participants were from: Northern America (USA, Canada), 21.8\% (520/2389); Europe, 46.8\% (1119/2389); and other international regions, 31.4\% (750/2389). Factors associated with some level of dissatisfaction with HIV medication among those otherwise fully satisfied with their HIV management included being on a multi-tablet regimen (AOR=2.76; 95\% CI: 1.93-3.96), reporting polypharmacy (AOR=2.10; 95\% CI: 1.45-3.03), and experiencing side effects from current HIV medication (AOR=2.12; 95\% CI: 1.49-3.02). Of seven improvements to HIV medications assessed, the percentage ranking each attribute, as the first or second most important, was: 'reduced long-term impact on my body'
\end{abstract}

(46.7\%); 'longer-lasting medicine so I don't have to take it every day' (43.1\%); 'fewer side effects' (40.5\%); 'less HIV medicine each day but just as effective' (25.4\%); 'less chance of affecting other medicines' (21.6\%); 'no food restrictions/ requirements' (14.0\%); and 'smaller pills' (8.7\%). Overall, $77.1 \%(1842 / 2389)$ believed 'future advances in HIV treatment will improve my overall wellbeing', $72.2 \%$ (1726/2389) were 'open to taking an HIV treatment composed of fewer medicines', while $54.7 \%(1306 / 2389)$ expressed openness towards longer-acting (non-daily) HIV medication. Compared to those not fully satisfied with either their HIV medication or management, those fully satisfied with both reported significantly higher prevalence of optimal treatment adherence $(89.2 \%$ [372/417] vs $69.5 \%$ [763/1098]) and optimal overall health $(70.3 \%[293 / 417]$ vs 47.8\% [525/1098]) (all $p<0.001$ ).

CONCLUSIONS Many PLHIV perceived gaps in their care and aspired for novel treatments. Providing flexible treatment options can help patients across the spectrum of unmet needs and improve health-related quality of life.

\section{INTRODUCTION}

Antiretroviral treatment (ART) can improve health outcomes among people living with HIV (PLHIV) and prevent onward HIV transmission ${ }^{1,2}$, yet, holistic patient care goes beyond medications. For PLHIV to thrive, not only survive, other components of HIV care need to be present ${ }^{3}$, including a non-judgmental and supportive clinical environment, peer support and counseling, well-coordinated care across disciplines; and quality communication with their healthcare providers (HCPs). High-value care that is both effective and efficient lies at the intersection of the best scientific evidence, the provider's clinical expertise, and the patient's preferences (i.e. evidence-based medicine) ${ }^{4,5}$.

Separating the perceived unmet needs of PLHIV between those that relate to broader HIV management issues versus those relating specifically to their HIV medication can help 
identify specific areas to improve the HIV care cascade. These overlapping, yet distinct, facets of patient care can influence each other in complex ways. For example, negative perceptions regarding quality of overall care received may sabotage adherence ${ }^{6}$. At the same time, medicationrelated challenges could also complicate overall treatment and adherence ${ }^{7-9}$. Other barriers to adherence include inconvenient dosing schedules, stigma, medication-related privacy concerns, emotional challenges, and polypharmacy (drug-drug interactions) ${ }^{10-13}$. There is therefore compelling need for flexible ART options that will meet the diversity of unmet medical, psychosocial, and emotional needs among PLHIV. Determining perceived gaps in care, as well as which treatment considerations are most important to patients with specific unmet needs can better help in tailoring treatment.

Currently there is no cure for HIV but there is plenty of research to suggest means for a functional cure may be available soon ${ }^{14,15}$. For example, long-acting cabotegravir and rilpivirine (CAB LA + RPV LA) is an innovative HIV treatment regimen that provides PLHIV with a long-acting treatment alternative that is as effective as daily oral ART ${ }^{14,15}$. This novel treatment, which eliminates the need for adherence to daily dosing, has significant potential to mitigate the substantial clinical and humanistic burden associated with daily oral ART. Administered parenterally, the new treatment may be beneficial to PLHIV with conditions that make oral administration of ART challenging (e.g. dysphagia, gastroesophageal reflux disease, and malabsorption), and for those at risk of drug-drug and drug-food interactions.

As the worldview in relation to patient care shifts from conquering diseases to promoting health and wellbeing ${ }^{16,17}$, and as PLHIV live longer ${ }^{18-20}$, treatment innovations that address the wide spectrum of patient unmet needs can help meet the fourth '90' target of improving quality of life among PLHIV ${ }^{17}$. Promising treatment innovations provide an anchor for patients' aspirations and may incentivize adherence to current treatment. Absent such advances in drug research and development, PLHIV may aspire for better treatment, yet feel nothing can be done, and therefore spiral into despair, nonadherence, and disengagement. However, knowing more is being done to develop treatment alternatives can provide hope and help PLHIV cope with their current treatment challenges. More so, discussing their treatment aspirations can build trust between patients and their providers and help in developing an ideal treatment plan to address identified concerns. PLHIV who are aware of ongoing advances in the field and their potential to positively impact patient care may also be more likely to participate in, and help improve the generalizability of clinical studies, which often underrepresent women and non-white ethnic groups ${ }^{21-23}$.

With the major strides in drug development, it is important to assess treatment aspirations among PLHIV, separate from their current treatment satisfaction, as these are distinct perceptions. To capture treatment aspirations among PLHIV in 25 countries during 2019, this study had the following objectives: 1) assess dissonance in perceived satisfaction with overall HIV management versus HIV medications; 2) identify what PLHIV consider as the 'most important improvements' to HIV medicines; and 3) explore factors associated with preference for innovative treatments.

\section{METHODS}

\section{Study population/sampling approach}

We conducted a web-based survey of 2389 PLHIV on ART, distributed in the following countries: USA (400), South Africa (179), Russia (150), United Kingdom (123), Australia (120), Canada (120), France (120), Germany (120), Italy (120), Spain (120), Japan (75), Mexico (63), Portugal (60), Brazil (58), Switzerland (55), Taiwan (55), Netherlands (51), Argentina (50), Austria (50), Chile (50), China (50), Ireland (50), Belgium (50), Poland (50), and South Korea (50). We recruited participants from existing panels of confirmed HIV seropositive individuals, as well as from support groups/ communities and online platforms. To better understand perceptions and attitudes of key population subgroups, sampling was purposive and aimed at achieving adequate sample sizes within three pre-specified strata: those diagnosed as HIV seropositive within the last two years, women, and persons aged $\geq 50$ years. Single IRB review for the multi-site study was done by the Pearl Institutional Review Board (no. 18-080622). In addition, specific approval for South Africa was obtained from the Sefako Makgatho Research Ethics Committee (no. SMUREC/M/223/2019). Participants provided written informed consent.

\section{Questionnaire development and fielding}

Development of the study instrument was done with input from PLHIV and an advisory panel of HIV physicians. Questionnaires were reviewed by local teams to ensure they were culturally and contextually appropriate. The survey instrument was pre-tested to ensure comprehension, flow, and online usability. The survey was administered in 20 languages: English, Canadian French, Latin American Spanish, Brazilian Portuguese, French, German, Italian, Spanish, Portuguese, Dutch, Flemish, Polish, Russian, Afrikaans, Zulu, Sotho, Japanese, Korean, Traditional Chinese, and Simplified Chinese. Translation of the English version of the screener and questionnaire to relevant local language(s) in each country was performed by medically trained translators through an iterative process to ensure accuracy. Once in the target language, additional trained translators proofread the questionnaire prior to final approval by local partners.

Data collection was done electronically using a web-based questionnaire that was self-completed by the respondent. The online questionnaire was rendered for ease of completion on all device types (mobile, tablet and laptop/ desktop) and major operating systems (IOS, Android); average completion time was 30 minutes. In a few instances where the respondent could not complete the survey unaided (e.g. because of limited literacy, language barrier, or lack of 
internet access), their answers were entered by a facilitator asking the questions directly to the respondent or entered by the respondent but with a facilitator on-hand to assist in case of any difficulty. Only in South Africa was this assisted mode of data collection used to a significant extent (29\%; 52/179 of South African participants).

\section{Measures}

PLHIV treatment experiences and challenges

Participants who rated their health as 'Good'/Very good' were classified as having 'optimal' health (vs 'Neither good nor poor' / 'Poor' / 'Very poor'). Polypharmacy was defined as taking $\geq 5$ pills/day for HIV and non-HIV conditions combined, or currently taking medicines for $\geq 5$ medical conditions, including HIV. Data were also collected on formulation of ART medications (single or multiple tablets), difficulty swallowing pills, treatment-related privacy concerns (hiding/disguising HIV medications within the past 6 months), frequency of missed ART doses in past month, and outlook towards dying prematurely from HIV. Poor self-prognosis regarding HIV mortality was an affirmative response ('Agree' or 'Strongly agree') to either statement below: 'HIV will reduce my life span' or 'Because of my HIV, I do not plan for my old age'. Participants were classified as experiencing side effects from their current HIV medication if they answered 'Agree' or 'Strongly' agree to the statement: 'My current HIV medication gives me side effects'. Presence of 'gastrointestinal side effects (stomach upset, stomachache/pain, diarrhea)', was further assessed among those reporting any side effects. Suboptimal adherence was defined as a report of $\geq 1$ reason for missing ART $\geq 5$ times within the past month.

\section{Perceived satisfaction with HIV medications and overall management}

Patient perception towards treatment is multidimensional; PLHIV may like certain aspects of their treatment (i.e. extent to which it meets their current needs), but not others (i.e. perceived gaps). We created separate derived variables indicating presence or absence of 'full' satisfaction with HIV medication and with HIV overall management, respectively. To achieve greater specificity in the definitions, each measure of 'full' satisfaction was derived from two variables measuring perceived satisfaction and perceived gaps. We classified PLHIV as perceiving they were fully satisfied with their HIV medication if they reported high levels of satisfaction with their 'current HIV medication' ('satisfied' or 'very satisfied') and at the same time did not strongly perceive that 'there is room for improvement with [their] current HIV medication' (scores of $\leq 3$ on a 1-5 ordinal scale); otherwise, they were classified as having some level of dissatisfaction with their current HIV medication. Likewise, PLHIV were classified as being fully satisfied with their overall HIV management if they reported high levels of satisfaction with 'the management of [their] HIV treatment' in relation to whether it met their personal needs/things most important to them (scores of $\geq 4$ on a 1-5 ordinal scale) and at the same time did not strongly perceive that 'I feel there is room for improving the way my HIV is managed' (scores of $\leq 3$ on a 1-5 ordinal scale); otherwise, they were classified as having some level of dissatisfaction with their overall HIV management. Using these two derived measures, we created a composite variable that assessed whether needs are fully met for management, needs are fully met for medication, and their interaction. With this composite variable, participants were classified as being fully satisfied with: 1) neither their broader HIV management nor their medication; 2) their HIV medication only; 3) their broader HIV management only; and 4) both their broader HIV management and medication. The survey also assessed various aspects of patient-provider communication and information sharing. Participants were further asked: 'When you first started HIV treatment, other than ensuring that it was effective, what were your most important considerations?'. Multiple responses could be selected.

Perception of 'most important' and 'least important' improvements to HIV medicines

We used an experimental design within the survey, known as Maximum Diffusion (MaxDiff), to evaluate which of the following seven potential improvements to HIV medicines was perceived to be most desirable to PLHIV: 'Smaller pills'; 'Fewer side effects'; 'Reduced long-term impact on my body'; 'Less chance of affecting other medicines/drugs/pills I take'; 'No food restrictions or requirements'; 'Less HIV medicine each day but just as effective'; and 'Longer-lasting medicine so I don't have to take it every day (e.g. a monthly injection administered by a doctor/nurse)'.

The research question we were exploring was: 'what is the order of patients' ranking of preferences or perceived importance for these seven treatment attributes?'. In the MaxDiff experiment, nine consecutive blocks (screens) were displayed, each block featuring three attributes selected at random. Participants rated which of the three attributes was, in their opinion, the 'Most important improvement', and which was the 'Least important'. A total of 2158 respondents completed the experiment; no significant differences were seen between these individuals versus the 231 participants who did not complete the experiment, in relation to key demographics including age, gender, and sexual orientation.

\section{Treatment aspirations}

The belief that 'future advances in HIV treatment will improve my overall health and wellbeing' was based on a response of 'Agree' or 'Strongly agree' (vs 'Neither agree nor disagree', 'Disagree', or 'Strongly disagree').

Besides assessing perceived importance of certain treatment attributes, the survey also measured participants' openness towards using novel HIV medications with some of those attributes, including ART with fewer medicines as well as long-acting regimen ${ }^{14,15}$. Openness towards long-acting 
regimens was defined as a response of 'Agree' or 'Strongly agree' to the statement: 'As long as my HIV stays suppressed, I would prefer not having to take HIV medication every day'. These two perceptions were not mutually exclusive. We previously reported the percentage of PLHIV open to HIV treatments composed of fewer medicines in preliminary analyses of our data from 24 countries. ${ }^{24}$ Here we provide an update of that estimate based on the full sample of 25 countries, along with additional multivariable analyses.

\section{Analyses}

The full sample size of 2389 was used for all analyses, except for the MaxDiff experiment which was completed by 2158 participants. Prevalence estimates for indicators of interest were calculated and compared with chi-squared tests. We used multivariable logistic regression analyses to explore factors associated with discordant perceptions regarding satisfaction with overall HIV management versus HIV medication, assessing for age, ethnicity, education, region, duration of disease, and gender. Exploratory logistic regression analyses were also performed among all participants to assess factors associated with openness towards taking an HIV medication with fewer medicines or a long-acting regimen.

To analyze the MaxDiff experiment, we generated variables for each possible allocation - a total of 63 new variables ( 9 blocks $\times 7$ attributes) ${ }^{25,26}$. For each of these 63 generated variables, possible codes assigned were: 0 (attribute shown but not selected); 1 (attribute ranked as 'Most important'); -1 (attribute ranked as 'Least important'); or missing (attribute not shown). To account for differential frequency of appearance of the different attributes, we created attribute-specific weights by dividing the number of times each attribute was selected by the number of times it appeared. We computed the weighted probabilities that each individual attribute was ranked in the 1 st, 2 nd, ...7th position; to minimize ties, very small, randomly generated numbers were added to each observation. Across all attributes, we also computed the 'preference shares' for the 1st through 7 th position or rank. The issue of which rank should be more relevant is determined purposefully, not statistically; here, we present the aggregate percentage of those who ranked each attribute in the first or second position as a measure of overall appeal. All analyses were performed with R v3.4.1. Statistical significance was set at $\mathrm{p}<0.05$.

\section{RESULTS}

Of the 2389 study participants, $41.2 \%$ were heterosexual, $45.8 \%$ were homosexual, while $13.0 \%$ identified as 'other sexual orientation'. By gender, 67.9\% identified as men, 29.1\% as women, and $2.9 \%$ as 'other gender' (Table 1). Of all study participants, $21.8 \%$ (520/2389) were from the USA/Canada, 46.8\% (1119/2389) from Europe, 9.2\% (221/2389) from Latin America, 9.6\% (230/2389) from Asia, 5.0\% (120/2389) from Australia, and 7.5\% (179/2389) from South Africa.

\section{Dissonance in satisfaction with HIV management vs medications}

Important treatment considerations at time of ART initiation among all participants included: 'to ensure side effects would be minimal', 53.8\% (1285/2389); 'to manage symptoms or illnesses caused by HIV', 51.6\% (1232/2389); 'to ensure that the virus was suppressed enough so that I could not pass it on to a partner', 49.1\% (1173/2389); 'to minimize the long-term impact of HIV treatment', $43.4 \%$ (1037/2389); 'to allow flexibility as to when I have to take the HIV medication (time of day, with or without food, etc.)', $35.4 \%$ (846/2389); 'to keep the number of HIV medicines in my treatment to a minimum', $34.8 \%$ (832/2389); 'that the treatment is available in my public health facility', $31.0 \%$ (741/2389); that the HIV medication 'was compatible with other medications/drugs/pills I was taking', $30.8 \%$ (737/2389); 'cost of the medication', 24.5\% (585/2389); and having 'the best option to allow me to have children', $16.8 \%$ (402/2389). Subgroup differences are shown in Table 1.

At the time of the survey, only $17.5 \%$ (417/2389) of all participants reported being fully satisfied with both their overall HIV management and medication: 26.8\% (639/2389) were fully satisfied with only their HIV medication, 9.8\% (235/2389) with only their overall HIV management, and $46.0 \%$ (1098/2389) with neither (Figure 1). Compared to those fully satisfied with neither their HIV medication nor overall management, those fully satisfied with both had higher prevalence of optimal adherence to treatment (89.2\% [372/417] vs 69.5\% [763/1098]), optimal overall health (70.3\% [293/417] vs 47.8\% [525/1098]), and a positive outlook for their HIV survival (67.6\% [282/417] vs $38.3 \%$ [420/1098]) (all p<0.001) (Figure 2). Among those fully satisfied with their HIV medication, 60.5\% (639/1056) reported some level of dissatisfaction with their overall HIV management, while $36.0 \%$ (235/652) of those fully satisfied with their overall HIV management reported some level of dissatisfaction with their HIV medication.

Factors associated with reporting some level of dissatisfaction with HIV medication among those otherwise fully satisfied with their overall HIV management included being on a multi-tablet regimen (AOR=2.76; 95\% CI: $1.93-$ 3.96), reporting polypharmacy (AOR $=2.10$; 95\% CI: $1.45-$ 3.03), and experiencing ART side effects (AOR=2.12; 95\% CI: 1.49-3.02) (Supplementary file, Figure S1). In contrast, the odds of reporting some level of dissatisfaction with HIV medication among those otherwise fully satisfied with their overall HIV management were lower among those who felt they understood enough about their treatment (AOR $=0.41$; 95\% CI: 0.27-0.62), and those who indicated that their HCP provided them with enough information to be involved in making decisions (AOR=0.45; 95\% CI: 0.31-0.67), sought their view before prescribing treatment (AOR=0.59; $95 \%$ CI: 0.41-0.86), inquired whether they had any treatment concerns (AOR=0.65; 95\% CI: 0.45-0.94), frequently asked if they were experiencing side effects $(\mathrm{AOR}=0.51$; 95\% CI: $0.35-$ 
Research Paper| Population Medicine

Table 1. Percentage of those who rated various treatment considerations as something important to them when they started their HIV treatment, People Living with HIV in 25 countries, Positive Perspectives Study, 2019 ( $\mathrm{N}=2389$ )

\begin{tabular}{|c|c|c|c|c|c|c|c|c|c|c|c|}
\hline & & $\begin{array}{l}\text { Minimizing } \\
\text { side effects }\end{array}$ & $\begin{array}{c}\text { Managing } \\
\text { illnesses } \\
\text { caused by } \\
\text { HIV }\end{array}$ & $\begin{array}{l}\text { Ensuring the } \\
\text { virus was } \\
\text { suppressed } \\
\text { to prevent } \\
\text { transmission }\end{array}$ & $\begin{array}{l}\text { Minimizing } \\
\text { long-term } \\
\text { side effects }\end{array}$ & $\begin{array}{c}\text { Flexible } \\
\text { dosing } \\
\text { schedule* }\end{array}$ & $\begin{array}{l}\text { Keeping the } \\
\text { number of } \\
\text { medicines } \\
\text { at a } \\
\text { minimum }\end{array}$ & $\begin{array}{c}\text { Ensuring } \\
\text { availability } \\
\text { in their } \\
\text { public } \\
\text { health } \\
\text { facility }\end{array}$ & $\begin{array}{c}\text { Ensuring } \\
\text { compatibility } \\
\text { with other } \\
\text { medications } \\
\text { taken }\end{array}$ & $\begin{array}{l}\text { Medication } \\
\text { costs }\end{array}$ & $\begin{array}{c}\text { Having the } \\
\text { best option } \\
\text { to have } \\
\text { children }\end{array}$ \\
\hline Category & n (\%) & $\%$ & $\%$ & $\%$ & $\%$ & $\%$ & $\%$ & $\%$ & $\%$ & $\%$ & $\%$ \\
\hline Total & $2389(100)$ & 53.8 & 51.6 & 49.1 & 43.4 & 35.4 & 34.8 & 31.0 & 30.8 & 24.5 & 16.8 \\
\hline \multicolumn{12}{|l|}{ Age (years) } \\
\hline$<50$ & $1690(71)$ & 51.3 & 49.0 & 50.2 & 42.7 & 36.7 & 33.7 & 31.8 & 30.4 & 25.3 & 21.2 \\
\hline$\geq 50$ & $699(29)$ & 59.8 & 57.8 & 46.4 & 45.1 & 32.2 & 37.6 & 29.0 & 32.0 & 22.5 & 6.2 \\
\hline \multicolumn{12}{|l|}{ Sexual orientation } \\
\hline Heterosexual & $984(41)$ & 48.7 & 48.9 & 44.9 & 39.9 & 33.5 & 33.4 & 32.1 & 32.7 & 25.2 & 28.2 \\
\hline Homosexual & $1094(46)$ & 59.5 & 53.0 & 53.7 & 46.3 & 38.0 & 34.8 & 31.0 & 28.8 & 22.4 & 5.7 \\
\hline Other & 311 (13) & 49.8 & 55.0 & 46.0 & 44.1 & 32.2 & 39.2 & 27.7 & 32.2 & 29.6 & 20.3 \\
\hline \multicolumn{12}{|l|}{ Gender } \\
\hline Other & $70(3)$ & 64.3 & 60.0 & 55.7 & 57.1 & 42.9 & 41.4 & 40.0 & 34.3 & 41.4 & 27.1 \\
\hline Woman & $696(29)$ & 48.3 & 50.1 & 43.8 & 38.8 & 32.2 & 32.9 & 29.0 & 31.3 & 22.4 & 22.6 \\
\hline \multicolumn{12}{|c|}{$\begin{array}{l}\text { Comorbidities ever } \\
\text { diagnosed }\end{array}$} \\
\hline None besides HIV & $993(42)$ & 46.0 & 43.5 & 46.4 & 39.4 & 33.1 & 33.7 & 28.9 & 24.2 & 26.5 & 20.0 \\
\hline One only & $470(20)$ & 60.4 & 51.5 & 51.1 & 47.2 & 37.2 & 34.7 & 34.3 & 36.0 & 26.8 & 18.1 \\
\hline Two or more & $926(39)$ & 58.7 & 60.3 & 51.0 & 45.8 & 36.9 & 36.1 & 31.6 & 35.4 & 21.2 & 12.7 \\
\hline \multicolumn{12}{|c|}{ Current co-treatments } \\
\hline None besides HIV & $1402(59)$ & 49.4 & 47.4 & 48.4 & 41.2 & 34.5 & 33.7 & 31.6 & 25.5 & 24.8 & 18.2 \\
\hline One only & $481(20)$ & 61.7 & 53.6 & 50.5 & 46.6 & 34.7 & 36.2 & 28.3 & 36.0 & 24.7 & 17.3 \\
\hline Two or more & $506(21)$ & 58.5 & 61.1 & 49.6 & 46.6 & 38.5 & 36.6 & 32.0 & 40.9 & 23.3 & 12.6 \\
\hline
\end{tabular}




\begin{tabular}{|c|c|c|c|c|c|c|c|c|c|c|c|}
\hline & & $\begin{array}{l}\text { Minimizing } \\
\text { side effects }\end{array}$ & $\begin{array}{l}\text { Managing } \\
\text { illnesses } \\
\text { caused by } \\
\text { HIV }\end{array}$ & $\begin{array}{l}\text { Ensuring the } \\
\text { virus was } \\
\text { suppressed } \\
\text { to prevent } \\
\text { transmission }\end{array}$ & $\begin{array}{l}\text { Minimizing } \\
\text { long-term } \\
\text { side effects }\end{array}$ & $\begin{array}{c}\text { Flexible } \\
\text { dosing } \\
\text { schedule* }\end{array}$ & $\begin{array}{l}\text { Keeping the } \\
\text { number of } \\
\text { medicines } \\
\text { at a } \\
\text { minimum }\end{array}$ & $\begin{array}{c}\text { Ensuring } \\
\text { availability } \\
\text { in their } \\
\text { public } \\
\text { health } \\
\text { facility }\end{array}$ & $\begin{array}{c}\text { Ensuring } \\
\text { compatibility } \\
\text { with other } \\
\text { medications } \\
\text { taken }\end{array}$ & $\begin{array}{l}\text { Medication } \\
\text { costs }\end{array}$ & $\begin{array}{c}\text { Having the } \\
\text { best option } \\
\text { to have } \\
\text { children }\end{array}$ \\
\hline Category & n (\%) & $\%$ & $\%$ & $\%$ & $\%$ & $\%$ & $\%$ & $\%$ & $\%$ & $\%$ & $\%$ \\
\hline \multicolumn{12}{|l|}{$\begin{array}{l}\text { Year of HIV } \\
\text { diagnosis }\end{array}$} \\
\hline 2017-2019 & $548(23)$ & 49.6 & 43.6 & 52.7 & 41.8 & 31.2 & 33.9 & 32.5 & 29.4 & 29.0 & 19.7 \\
\hline $2010-2016$ & $913(38)$ & 53.5 & 48.2 & 52.1 & 43.2 & 36.6 & 33.8 & 31.3 & 32.9 & 25.6 & 19.7 \\
\hline Pre-2010 & $928(39)$ & 56.6 & 59.6 & 44.0 & 44.6 & 36.7 & 36.3 & 29.8 & 29.7 & 20.7 & 12.3 \\
\hline \multicolumn{12}{|l|}{ Location of PLHIV } \\
\hline Metropolitan & $1335(56)$ & 57.2 & 54.5 & 53.0 & 45.8 & 36.8 & 37.1 & 33.0 & 30.0 & 24.4 & 14.5 \\
\hline Non-metropolitan & $1054(44)$ & 49.4 & 47.8 & 44.1 & 40.4 & 33.7 & 32.0 & 28.6 & 31.9 & 24.6 & 19.7 \\
\hline \multicolumn{12}{|l|}{$\begin{array}{l}\text { Duration of HIV } \\
\text { years (pentiles) }\end{array}$} \\
\hline $\begin{array}{l}\text { Bottom one-fifth } \\
(20 \% \text { most recently } \\
\text { diagnosed) }\end{array}$ & $548(23)$ & 49.6 & 43.6 & 52.7 & 41.8 & 31.2 & 33.9 & 32.5 & 29.4 & 29.0 & 19.7 \\
\hline $\begin{array}{l}\text { Second lowest one- } \\
\text { fifth }\end{array}$ & $469(20)$ & 49.9 & 43.7 & 51.8 & 40.9 & 34.3 & 30.7 & 31.3 & 35.4 & 27.5 & 18.8 \\
\hline Third lowest one-fifth & 444 (19) & 57.2 & 52.9 & 52.5 & 45.5 & 39.0 & 37.2 & 31.3 & 30.2 & 23.6 & 20.7 \\
\hline $\begin{array}{l}\text { Fourth lowest one- } \\
\text { fifth }\end{array}$ & 451 (19) & 57.9 & 56.3 & 47.2 & 48.1 & 38.6 & 37.7 & 31.5 & 28.8 & 19.5 & 15.3 \\
\hline Top $20 \%$ of duration & $477(20)$ & 55.3 & 62.7 & 40.9 & 41.3 & 35.0 & 35.0 & 28.3 & 30.6 & 21.8 & 9.4 \\
\hline \multicolumn{12}{|l|}{ Employment } \\
\hline Employed & $1653(69)$ & 52.9 & 47.4 & 50.3 & 41.6 & 35.5 & 34.4 & 30.4 & 30.7 & 25.3 & 16.2 \\
\hline Non employed & $736(31)$ & 55.8 & 61.0 & 46.3 & 47.6 & 35.2 & 35.7 & 32.3 & 31.1 & 22.7 & 18.3 \\
\hline \multicolumn{12}{|l|}{ Education } \\
\hline High school or less & $532(22)$ & 50.8 & 53.4 & 47.4 & 41.4 & 36.1 & 33.1 & 32.5 & 29.9 & 24.8 & 15.6 \\
\hline
\end{tabular}

ART: antiretroviral treatment. *For example, with food. 
Figure 1. Percentage of PLHIV who reported being fully satisfied with neither their HIV medication nor their overall HIV management, with their HIV medication only, with their overall HIV management only, and with both their HIV medication and overall management, among persons living with HIV in 25 countries, Positive Perspectives Study, 2019 ( $\mathrm{N}=2389$ )

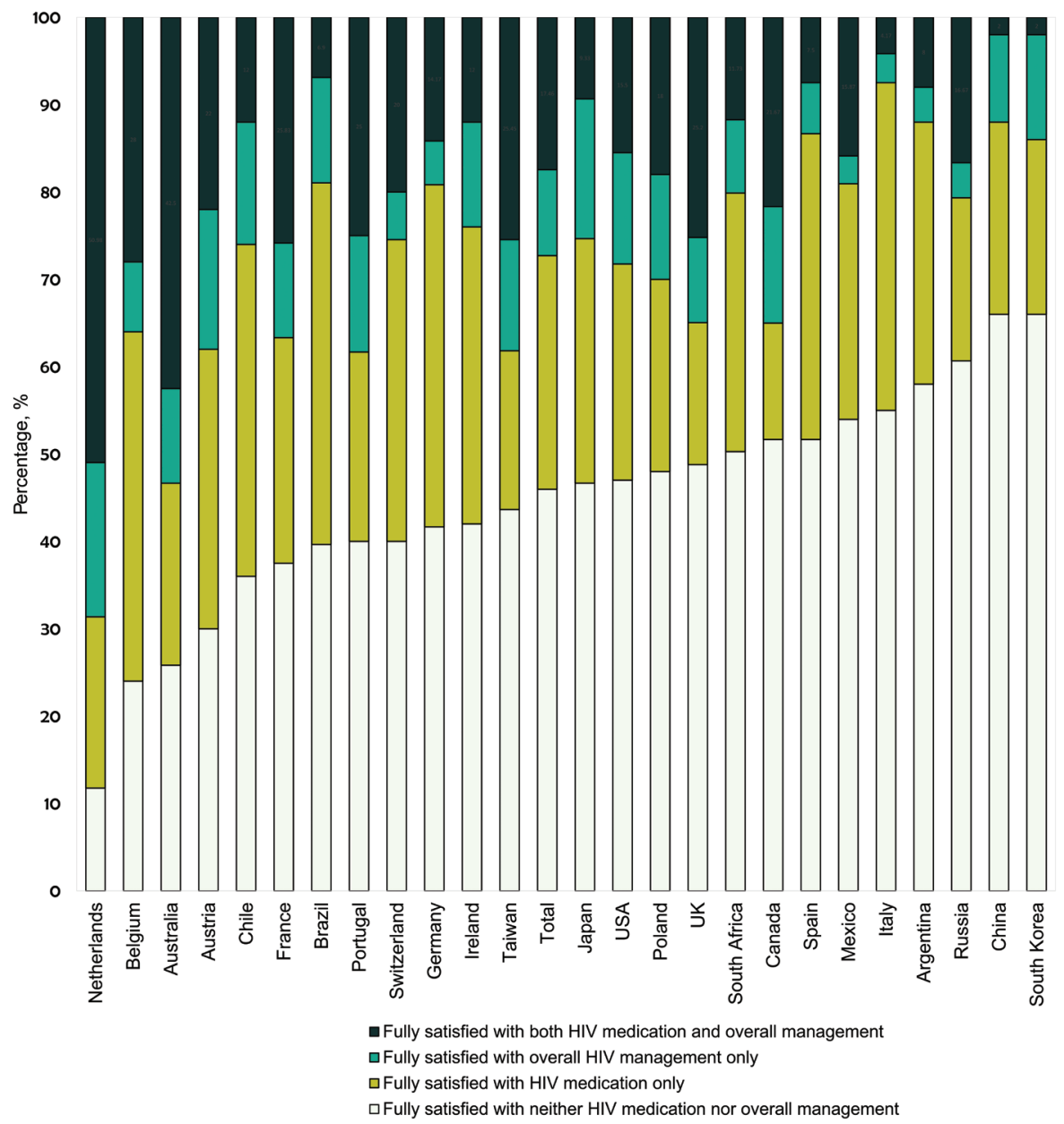

$0.73)$, or told them the benefits of being virally undetectable (i.e. Undetectable $=$ Untransmittable; AOR $=0.38 ; 95 \%$ CI: 0.26-0.55). Individuals with optimal self-rated health in the various domains assessed, were also less likely to report some level of dissatisfaction with their HIV medication among those otherwise fully satisfied with their overall HIV management. Among those otherwise fully satisfied with their HIV medication, perception of some level of dissatisfaction with their broader HIV management was associated with poor patient-provider communication and experience of side effects as shown in Supplementary file, Figure S1.

\section{Perceived appeal of various potential improvements to HIV medicines}

Of the seven potential improvements to HIV medicines evaluated within the MaxDiff experiment, the percentage of PLHIV who ranked each attribute as either the first or second most important was: 'reduced long-term impact on my body'
(46.7\%); 'longer-lasting medicine so I don't have to take it every day' (43.1\%); 'fewer side effects' (40.5\%); 'less HIV medicine each day but just as effective' (25.4\%); less chance of affecting other medicines/drugs/pills I take' (21.6\%); 'no food restrictions or requirements' (14.0\%); and 'smaller pills' (8.7\%) (Figure 3).

In terms of individual ranks, the attributes with the largest preference shares for the top (i.e. first) position were 'longerlasting medicine so I don't have to take it every day' (25.9\%), followed by 'reduced long-term impact on my body' (23.3\%) and 'fewer side effects' (19.6\%). For the second position, the largest preference shares were for 'reduced long-term impact on my body' (23.4\%), 'fewer side effects' (20.9\%), and 'longer-lasting medicine so I don't have to take it every day' (17.2\%). For the third position, the largest preference shares were for 'reduced long-term impact on my body' (19.2\%), 'less HIV medicine each day but just as effective' (18.5\%), and 'fewer side effects' (18.1\%). 
Figure 2. Attitudes, behaviors, and other health outcomes among people living with HIV, stratified by perceived satisfaction with overall HIV management and HIV medication, Positive Perspectives Study, 2019 (N=2389)

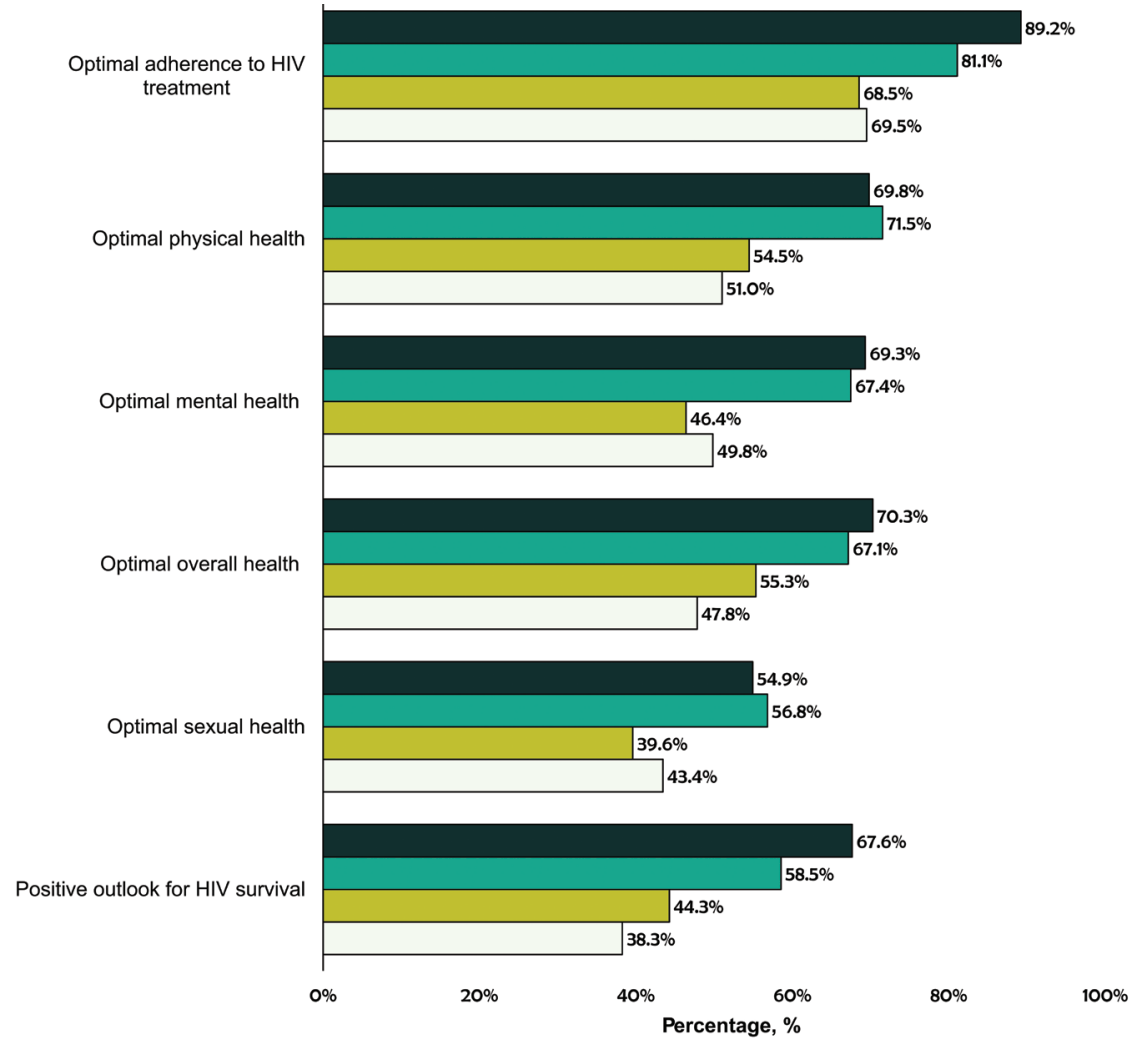

घully satisfied with both HIV medication and overall HIV management 口Fully satisfied with only HIV medication

口Fully satisfied with only overall HIV management

口Fully satisfied with neither HIV medication nor overall HIV management

Figure 3. Preference shares for the seven attributes of HIV medicines assessed among people living with HIV in 25 countries, 2019, ranked by order of overall appeal

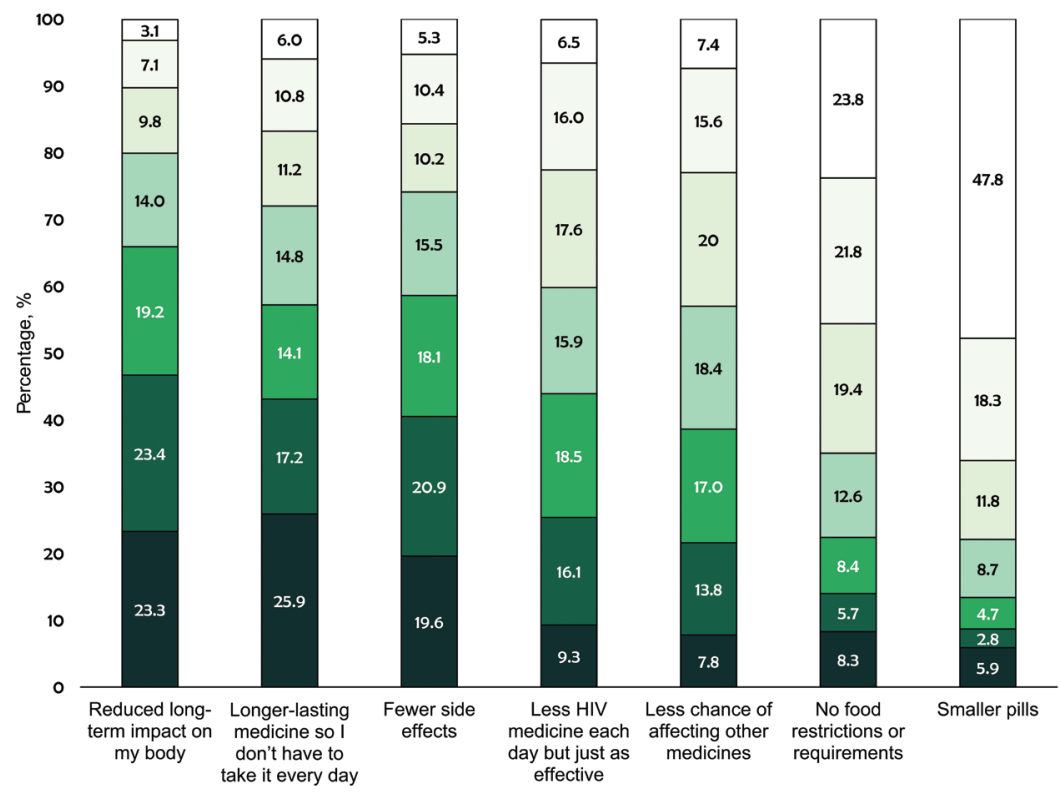




\section{Treatment aspirations}

Overall, 77.1\% (1842/2389) of all participants believed that 'future advances in HIV care will improve [their] overall health and wellbeing. This aspiration was highest among those who were fully satisfied with their HIV medication only (85.3\%, 545/639) and lowest among those fully satisfied with their overall HIV management only (68.1\%, 160/235); the two groups at the extremes - those fully satisfied with both, or with neither - reported prevalence of $78.7 \%$ (328/417) and 73.7\% (809/1098), respectively ( $p=0.046)$. Those fully satisfied with neither their medication nor management differed significantly in this aspiration when compared with those fully satisfied with their medication only $(\mathrm{p}<0.001)$ but did not differ significantly from those fully satisfied with their overall HIV management only $(p=0.081)$.

Of all participants, $72.2 \%$ (1726/2389) were 'open to taking an HIV treatment composed of fewer medicines', and $54.7 \%$ (1306/2389) indicated preference for a long-acting regimen; country-specific estimates are given in Figure 4. Medication-related privacy concerns were not significantly associated with openness to taking an HIV treatment with fewer medicines but were associated with preference for a long-acting regimen (Table 2); those who ever hid/disguised their HIV medicines had 28\% higher odds of preferring a long-acting regimen (AOR=1.28; 95\% CI: 1.06-1.55). With increases in the maximum number of times ART was missed for any given reason in the past month, odds of being open to taking an HIV treatment with fewer medicines decreased (AOR=0.69 and 0.56 , for $2-4$ and $\geq 5$ times of missed dose, respectively, all $\mathrm{p}<0.05)$. Conversely, those missing ART for up to 2-4 and $\geq 5$ times within the past month for any reason had $29 \%$ and $38 \%$ higher odds of preferring a long-acting regimen, respectively, compared to those with no missed dose (all $\mathrm{p}<0.05$ ). Those who had ever changed their ART $\geq 2$ times had higher odds of being open to an HIV treatment with fewer medicines (AOR=1.72; 95\% CI: 1.31-2.26) and

Figure 4. Percentage of people living with HIV in 25 countries who indicated preference for a long-acting (non-daily) regimen or an HIV treatment with fewer number of medicines, Positive Perspectives Study, 2019 $(\mathrm{N}=2389)$

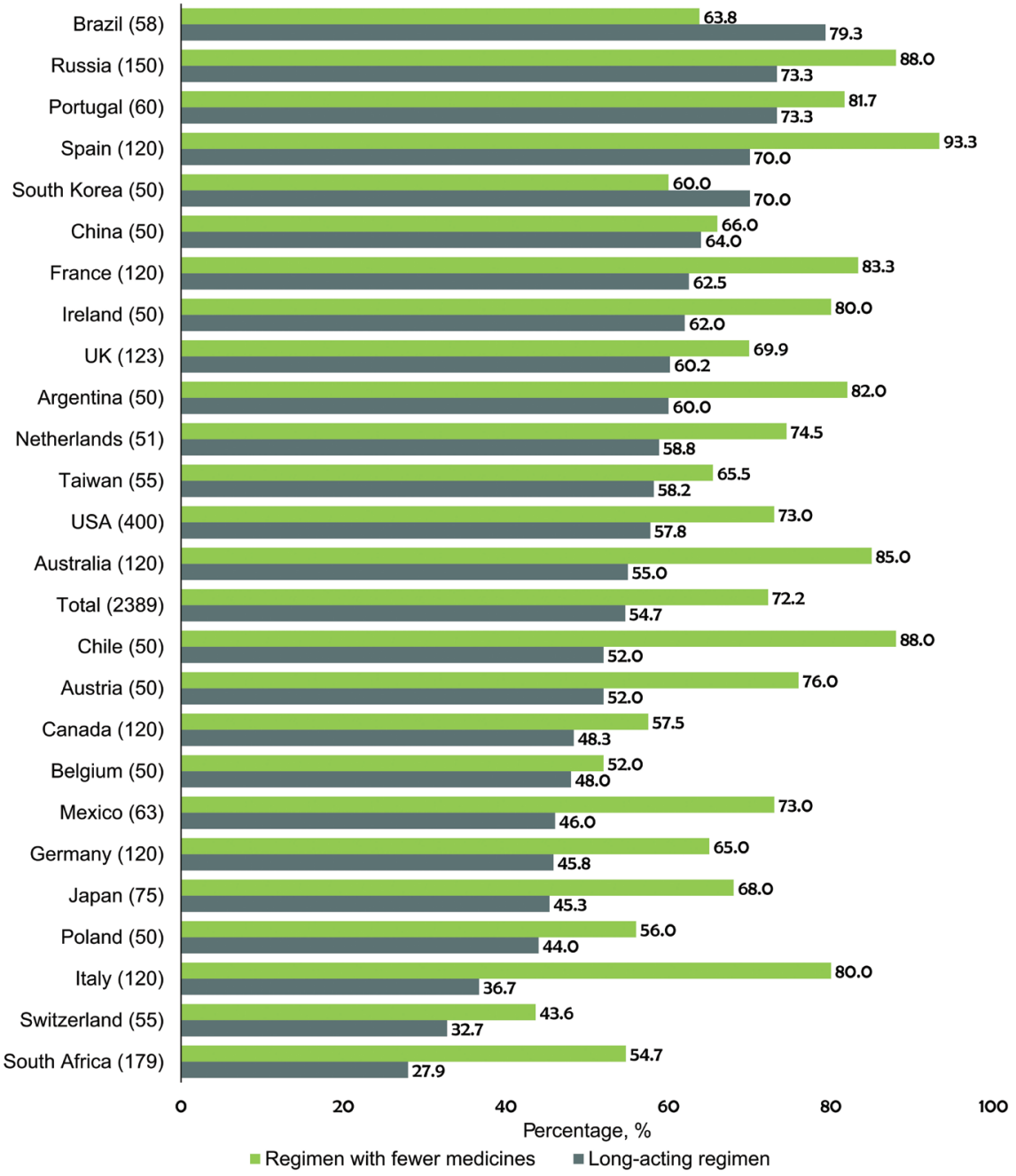


Table 2. Multivariable logistic regression analyses of factors associated with being open to taking an HIV treatment with fewer medicines as well as preference for long-acting regimen among all participants, Positive Perspectives Study, 2019 (N=2389)

\begin{tabular}{|c|c|c|c|c|c|c|}
\hline \multirow[t]{2}{*}{ Characteristic } & \multirow[t]{2}{*}{ Categories } & \multirow[t]{2}{*}{$\mathbf{N}$} & \multicolumn{2}{|c|}{$\begin{array}{l}\text { HIV Treatment with fewer } \\
\text { medicines }\end{array}$} & \multicolumn{2}{|c|}{$\begin{array}{c}\text { Longer-acting (non-daily) } \\
\text { ART regimens }\end{array}$} \\
\hline & & & AOR (95\% CI) & $\mathbf{p}$ & AOR (95\% CI) & $\mathbf{p}$ \\
\hline \multirow{4}{*}{$\begin{array}{l}\text { Perception regarding } \\
\text { medication } \\
\text { and overall HIV } \\
\text { management }\end{array}$} & $\begin{array}{l}\text { Fully satisfied with neither HIV } \\
\text { medication nor management (Ref.) }\end{array}$ & 1098 & & & & \\
\hline & $\begin{array}{l}\text { Fully satisfied with HIV medication } \\
\text { only }\end{array}$ & 639 & $1.28(1.01-1.63)$ & 0.044 & $0.74(0.60-0.91)$ & 0.005 \\
\hline & $\begin{array}{l}\text { Fully satisfied with overall HIV } \\
\text { management only }\end{array}$ & 235 & $0.93(0.68-1.29)$ & 0.678 & $0.73(0.54-0.98)$ & 0.039 \\
\hline & $\begin{array}{l}\text { Fully satisfied with both HIV } \\
\text { medication and management }\end{array}$ & 417 & $0.96(0.72-1.29)$ & 0.805 & $0.52(0.40-0.67)$ & $<0.001$ \\
\hline \multirow[t]{3}{*}{ Side effects from ART } & None (Ref.) & 1348 & & & & \\
\hline & Non-gastrointestinal only & 356 & $1.06(0.81-1.40)$ & 0.664 & $1.18(0.92-1.52)$ & 0.188 \\
\hline & Gastrointestinal & 685 & $1.63(1.28-2.07)$ & $<0.001$ & $1.74(1.41-2.15)$ & $<0.001$ \\
\hline \multirow{3}{*}{$\begin{array}{l}\text { Non-HIV } \\
\text { comorbidities }\end{array}$} & None (Ref.) & 993 & & & & \\
\hline & 1 only & 470 & $1.05(0.81-1.37)$ & 0.711 & $1.12(0.88-1.43)$ & 0.352 \\
\hline & $\geq 2$ & 926 & $1.21(0.95-1.54)$ & 0.128 & $1.31(1.05-1.63)$ & 0.015 \\
\hline \multirow{2}{*}{$\begin{array}{l}\text { Ever hid/disguised } \\
\text { ART in past } 6 \text { months }\end{array}$} & No (Ref.) & 1006 & & & & \\
\hline & Yes & 1383 & $1.01(0.81-1.25)$ & 0.961 & $1.28(1.06-1.55)$ & 0.011 \\
\hline \multirow{4}{*}{$\begin{array}{l}\text { Maximum number of } \\
\text { times missed ART in } \\
\text { past month for any } \\
\text { given reason }\end{array}$} & None (Ref.) & 690 & & & & \\
\hline & 1 & 563 & $1.03(0.77-1.37)$ & 0.856 & $1.23(0.97-1.56)$ & 0.092 \\
\hline & $2-4$ & 561 & $0.69(0.52-0.91)$ & 0.009 & $1.29(1.01-1.66)$ & 0.044 \\
\hline & $\geq 5$ & 575 & $0.56(0.42-0.74)$ & $<0.001$ & $1.38(1.07-1.78)$ & 0.015 \\
\hline \multirow{2}{*}{$\begin{array}{l}\text { Self-reported viral } \\
\text { status }\end{array}$} & Non-suppressed/unknown & 619 & & & & \\
\hline & Suppressed & 1770 & $1.03(0.81-1.31)$ & 0.822 & $1.07(0.85-1.34)$ & 0.574 \\
\hline \multirow[t]{3}{*}{ Diagnosis year } & 2017-19 (Ref.) & 548 & & & & \\
\hline & $2010-16$ & 913 & $0.79(0.61-1.02)$ & 0.071 & $0.70(0.55-0.88)$ & 0.003 \\
\hline & Pre-2010 & 928 & $0.78(0.57-1.05)$ & 0.101 & $0.69(0.52-0.91)$ & 0.008 \\
\hline \multirow[t]{3}{*}{ Gender } & Male (Ref.) & 1623 & & & & \\
\hline & Other & 70 & $1.96(1.06-3.64)$ & 0.032 & $1.05(0.61-1.80)$ & 0.856 \\
\hline & Female & 696 & $0.93(0.75-1.15)$ & 0.492 & $1.07(0.88-1.30)$ & 0.513 \\
\hline \multirow[t]{3}{*}{ Education } & $\leq$ High school (Ref.) & 532 & & & & \\
\hline & > High school & 1756 & $1.20(0.95-1.51)$ & 0.121 & $1.13(0.92-1.40)$ & 0.251 \\
\hline & Unknown & 101 & $0.26(0.16-0.44)$ & $<0.001$ & $0.62(0.37-1.02)$ & 0.061 \\
\hline \multirow[t]{6}{*}{ Geographic region } & Northern America (Ref.) & 520 & & & & \\
\hline & Europe & 1119 & $1.27(0.98-1.64)$ & 0.073 & $1.25(0.99-1.58)$ & 0.064 \\
\hline & Latin America & 221 & $1.13(0.76-1.66)$ & 0.546 & $1.03(0.73-1.46)$ & 0.855 \\
\hline & Asia & 230 & $0.85(0.60-1.21)$ & 0.372 & $1.03(0.74-1.45)$ & 0.851 \\
\hline & Australia & 120 & $1.86(1.05-3.27)$ & 0.032 & $1.23(0.80-1.90)$ & 0.348 \\
\hline & South Africa & 179 & $0.83(0.55-1.24)$ & 0.359 & $0.41(0.27-0.62)$ & $<0.001$ \\
\hline \multirow[t]{2}{*}{ PLHIV location } & Metropolitan & 1335 & & & & \\
\hline & Non-metropolitan & 1054 & $0.75(0.61-0.91)$ & 0.004 & $0.78(0.65-0.93)$ & 0.006 \\
\hline
\end{tabular}


Table 2. Continued

\begin{tabular}{|c|c|c|c|c|c|c|}
\hline \multirow[t]{2}{*}{ Characteristic } & \multirow[t]{2}{*}{ Categories } & \multirow[t]{2}{*}{$\mathbf{N}$} & \multicolumn{2}{|c|}{$\begin{array}{l}\text { HIV Treatment with fewer } \\
\text { medicines }\end{array}$} & \multicolumn{2}{|c|}{$\begin{array}{l}\text { Longer-acting (non-daily) } \\
\text { ART regimens }\end{array}$} \\
\hline & & & AOR (95\% CI) & $\mathbf{p}$ & AOR (95\% CI) & $\mathbf{p}$ \\
\hline \multirow{3}{*}{$\begin{array}{l}\text { Number of times ever } \\
\text { changed ART }\end{array}$} & Never (Ref.) & 699 & & & & \\
\hline & 1 time & 626 & $1.05(0.81-1.37)$ & 0.702 & $1.11(0.87-1.43)$ & 0.395 \\
\hline & $\geq 2$ times & 1064 & $1.72(1.31-2.26)$ & $<0.001$ & $1.33(1.04-1.70)$ & 0.025 \\
\hline \multirow{4}{*}{$\begin{array}{l}\text { Ever wanted an HIV } \\
\text { treatment different } \\
\text { from that they were } \\
\text { taking }\end{array}$} & No (Ref.) & 1119 & & & & \\
\hline & Yes, but never discussed with HCP & 304 & $0.92(0.68-1.26)$ & 0.618 & $1.23(0.93-1.64)$ & 0.146 \\
\hline & $\begin{array}{l}\text { Yes, but was not prescribed after } \\
\text { discussing with HCP }\end{array}$ & 348 & $1.45(1.05-2.00)$ & 0.023 & $1.47(1.12-1.91)$ & 0.005 \\
\hline & $\begin{array}{l}\text { Yes, and was prescribed after } \\
\text { discussing with HCP }\end{array}$ & 618 & $0.87(0.67-1.14)$ & 0.313 & $0.94(0.74-1.19)$ & 0.588 \\
\hline
\end{tabular}

AOR: adjusted odds ratios. ART: antiretroviral therapy. HCP: healthcare provider. PLHIV: people living with HIV. Regression analyses controlled for all factors listed in table. Statistically significance was set at p<0.05. Ref.: reference. Countries by region were: Northern America (U.S. and Canada); Europe (Austria, Belgium, France, Germany, Italy, the Netherlands, Poland, Portugal, Ireland, Russia, Spain, Switzerland, and the UK); Latin America (Argentina, Brazil, Chile, and Mexico), Asia (China, Japan, South Korea, and Taiwan).

also preferring a long-acting regimen $(\mathrm{AOR}=1.33 ; 95 \% \mathrm{CI}$ : 1.04-1.70). Compared to those who never wanted a different HIV medication than the one they were currently on, those who ever wanted one in the past but were not prescribed after discussing with their HCP were more likely to be open to an HIV treatment with fewer medicines (AOR=1.45; $95 \%$ CI: 1.05-2.00), as well as preferring a longer-acting regimen (AOR=1.47; 95\% CI: 1.12-1.91). Those fully satisfied with their HIV medication had lower odds of preferring a longacting regimen (AOR=0.74; 95\% CI: 0.60-0.91), but reported higher odds of being open to taking an HIV treatment with fewer medicines (AOR=1.28; 95\% CI: 1.01-1.63). PLHIV who lived in a non-metropolitan area had lower odds than those in a metropolitan area of being open to taking an HIV treatment with fewer medicines $(\mathrm{AOR}=0.75$; $95 \% \mathrm{CI}$ : $0.61-0.91$ ) or preferring a long-acting regimen $(\mathrm{AOR}=0.78$; 95\% CI: 0.65-0.93). Compared to newly diagnosed PLHIV (2017-2019), odds of preferring a long-acting regimen were significantly lower among those diagnosed during 2010-16 $(A O R=0.70 ; 95 \%$ CI: 0.55-0.88) and pre-2010 (AOR=0.69; 95\% CI: 0.52-0.91). Compared to PLHIV in Northern America, those in Australia had 86\% higher odds of being open to an HIV treatment with fewer medicines (AOR=1.86; 95\% CI: 1.05-3.27) while those in South Africa had 59\% lower odds of indicating preference for longer-acting regimens $(\mathrm{AOR}=0.41$; 95\% CI: 0.27-0.62). Having $\geq 2$ comorbidities was positively associated with $31 \%$ higher odds of preferring a long-acting regimen, compared to not having any comorbidity (AOR=1.31; 95\% CI: 1.05-1.63, Table 2).

\section{DISCUSSION}

Less than 1 in 5 (17.5\%) of PLHIV were fully satisfied with both their overall HIV management and medications, whereas over 4 in 5 perceived gaps in either their overall HIV management or their medication. Among those otherwise fully satisfied with their overall HIV management, over 1 in 3 (36\%) reported some level of dissatisfaction with their HIV medication, especially those experiencing side effects, with polypharmacy, and on multi-tablet ART regimens. On the other hand, among those fully satisfied with their HIV medication, factors like polypharmacy, tablet formulation, or self-rated health status, were not found to be significantly associated with perceived gaps in overall HIV management. The top three treatment attributes perceived as most important were medicines with reduced long-term adverse impact, longer-lasting medicine that eliminated the need for daily intake, and those with fewer side effects.

Enhanced and sustained efforts to improve quality of life among PLHIV must involve holistic care as our results showed that 3 in 5 (60.5\%) PLHIV who were fully satisfied with their medication still perceived gaps in their overall HIV management. Notably, the highest percentage of those believing that future advances in HIV treatment will improve their overall wellbeing was seen among PLHIV reporting full satisfaction with their HIV medication only, underscoring the impact of HIV treatment on quality of life, even among those with the most favorable perceived treatment experiences currently. Addressing patients' preferences and concerns is key to meeting the fourth ' 90 ' target, ensuring that PLHIV not only survive, but thrive ${ }^{16,17}$. Besides ensuring patient convenience, improved quality of life can mitigate treatment failure by tackling the chief causes of non-adherence ${ }^{27}$, including emotional challenges and psychosocial barriers.

The success of treatment goals may depend on perceived facilitators and impediments at the level of the patient (e.g. lifestyle factors), the disease (e.g. chronicity), treatment of the disease (e.g. side effects), and patient relationship with healthcare providers (e.g. perceived involvement in care $)^{28}$. 
In our study, preferences were varied, as were individual circumstances. Study participants who had some unmet needs or constraints with their current treatment (e.g. privacy concerns, poor adherence, and polypharmacy), were all more likely to prefer a long-acting injectable regimen. Several studies have shown a relationship between treatment satisfaction and adherence to daily oral ART, suggesting that providing PLHIV and HCPs with treatment options they value may help further increase treatment adherence, retention in care, and quality of life of PLHIV ${ }^{29-32}$. Providing flexible treatment options can help patients across the spectrum of unique medical and non-medical needs, to optimize healthrelated outcomes. Our observation of improved indicators of quality of life among those fully satisfied with both their medication and their overall care makes intensified efforts towards holistic HIV care paramount.

\section{Strengths and limitations}

This study's strengths include the collection of information from a large sample of participants from 25 countries using a standardized instrument. It is important to note that this population is not the general population but, rather, is a population of confirmed HIV seropositive individuals, which is a significant strength of the study. In evaluating treatment preferences of PLHIV, we used an experimental technique (Maximum Diffusion) for more robust preference identification under possible inconsistent choice behavior. Some limitations however exist. First, the online fielding of the survey could have limited participation for those with computer literacy and internet access. Second, these data are cross-sectional in nature and only associations can be drawn. Third, participants were selected non-probabilistically, which may limit study generalizability. Selection of eligible countries was also driven by logistical considerations not purely by burden of disease. Despite these limitations, these study findings draw attention to the need for holistic HIV care to improve health outcomes among PLHIV.

\section{CONCLUSIONS}

Overall, only $17.5 \%$ were fully satisfied with both their overall HIV management and HIV medication. Furthermore, 72.2\% were open to taking an HIV treatment with fewer medicines, and $54.7 \%$ preferred a long-acting regimen. Preference for a long-acting injectable regimen was higher among those with comorbidities, with suboptimal adherence, and those experiencing ART side effects. The top three treatment improvements perceived as most important were HIV medicines with reduced long-term adverse impact, longer-lasting medicines that eliminated the need for daily intake, and those with fewer side effects. Providing flexible treatment options can help patients across the spectrum of unique medical needs and preferences to improve their health-related quality of life.

\section{REFERENCES}

1. Nachega JB, Marconi VC, van Zyl GU, et al. HIV treatment adherence, drug resistance, virologic failure: evolving concepts. Infect Disord Drug Targets. 2011;11(2):167-174. doi:10.2174/187152611795589663

2. Nachega JB, Hislop M, Dowdy DW, et al. Adherence to highly active antiretroviral therapy assessed by pharmacy claims predicts survival in HIV-infected South African adults. J Acquir Immune Defic Syndr. 2006;43(1):78-84. doi:10.1097/01.qai.0000225015.43266.46

3. U.S. Department of Health and Human Services, Health Resources and Services Administration, Guide for HIV/AIDS Clinical Care - 2014 Edition. Rockville, MD: U.S. Department of Health and Human Services; 2014. Available at https:// hab.hrsa.gov/sites/default/files/hab/clinical-qualitymanagement/2014guide.pdf. Accessed March 20, 2020.

4. Sackett DL, Rosenberg WMC, Gray JAM, Haynes RB, Richardson WS. Evidence based medicine: what it is and what it isn't. BMJ. 1996;312(7023):71-72. doi:10.1136/bmj.312.7023.71

5. Lyu H, Xu T, Brotman D, et al. Overtreatment in the United States. PLoS ONE. 2017;12(9):e0181970. doi:10.1371/journal.pone.0181970

6. St Clair-Sullivan N, Mwamba C, Whetham J, Bolton Moore C, Darking M, Vera J. Barriers to HIV care and adherence for young people living with HIV in Zambia and mHealth. Mhealth. 2019;5:45. doi:10.21037/mhealth.2019.09.02

7. Iacob SA, Iacob DG, Jugulete G. Improving the adherence to antiretroviral therapy, a difficult but essential task for a successful hiv treatment-clinical points of view and practical considerations. Front Pharmacol. 2017;8:831. doi:10.3389/fphar.2017.00831

8. Haberer JE, Sabin L, Amico KR, et al. Improving antiretroviral therapy adherence in resource-limited settings at scale: a discussion of interventions and recommendations. J Int AIDS Soc. 2017;20(1):21371. doi:10.7448/IAS.20.1.21371

9. Yu Y, Luo D, Chen X, Huang Z, Wang M, Xiao S. Medication adherence to antiretroviral therapy among newly treated people living with HIV. BMC Public Health. 2018;18(1):825. doi:10.1186/s12889-018-5731-z

10. Holtzman CW, Brady KA, Yehia BR. Retention in care and medication adherence: current challenges to antiretroviral therapy success. Drugs. 2015;75(5):445-454. doi:10.1007/s40265-015-0373-2

11. Simoni JM, Frick PA, Pantalone DW, Turner BJ. Antiretroviral adherence interventions: a review of current literature and ongoing studies. Top HIV Med. 2003;11(6):185-198. PMID:14724327.

12. Bukenya D, Mayanja BN, Nakamanya S, Muhumuza R, Seeley $\mathrm{J}$. What causes non-adherence among some individuals on long term antiretroviral therapy? Experiences of individuals with poor viral suppression in Uganda. AIDS Res Ther. 2019;16(1):2. doi:10.1186/s12981-018-0214-y

13. Catz SL, Kelly JA, Bogart LM, Benotsch EG, McAuliffe TL. Patterns, correlates, and barriers to medication adherence among persons prescribed new treatments for HIV disease. Health Psychol. 2000;19(2):124-133. doi:10.1037/0278-6133.19.2.124

14. Margolis DA, Gonzalez-Garcia J, Stellbrink HJ, et al. Long-acting intramuscular cabotegravir and rilpivirine 
in adults with HIV-1 infection (LATTE-2): 96-week results of a randomised, open-label, phase $2 \mathrm{~b}$, noninferiority trial. Lancet. 2017;390(10101):1499-1510. doi:10.1016/S0140-6736(17)31917-7

15. Margolis DA, Brinson CC, Smith GHR, et al. Cabotegravir plus rilpivirine, once a day, after induction with cabotegravir plus nucleoside reverse transcriptase inhibitors in antiretroviralnaive adults with HIV-1 infection (LATTE): a randomised, phase 2b, dose-ranging trial. Lancet Infect Dis. 2015;15(10):11451155. doi:10.1016/S1473-3099(15)00152-8

16. Joint United Nations. 90-90-90: an ambitious treatment target to help end the AIDS epidemic. Geneva, Switzerland: Unaids; 2014. https://www.unaids.org/sites/default/files/ media_asset/90-90-90_en.pdf. Accessed June 20, 2020.

17. Lazarus JV, Safreed-Harmon K, Barton SE, et al. Beyond viral suppression of HIV-the new quality of life frontier. BMC Medicine. 2016;14(1):94. doi:10.1186/s12916-016-0640-4

18. Mahy M, Autenrieth CS, Stanecki K, Wynd S. Increasing trends in HIV prevalence among people aged 50 years and older: evidence from estimates and survey data. AIDS. 2014;28(4):S453-S459. doi:10.1097/qad.0000000000000479

19. UNAIDS. HIV and Aging: A special supplement to the UNAIDS report on the global AIDS epidemic 2013. https://reliefweb. int/sites/reliefweb.int/files/resources/HIV-and-Aging.pdf. Accessed June 20, 2020.

20. Lima VD, Harrigan R, Bangsberg DR, et al. The combined effect of modern highly active antiretroviral therapy regimens and adherence on mortality over time. J Acquir Immune Defic Syndr. 2009;50(5):529-536. doi:10.1097/QAI.0b013e31819675e9

21. Barr L, Jefferys R. A landscape analysis of HIV cure-related clinical trials and observational studies in 2018. J Virus Erad. 2019;5(4):212-219. doi:10.1016/s2055-6640(20)30030-3

22. Moore DA, Goodall RL, Ives NJ, Hooker M, Gazzard BG, Easterbrook PJ. How generalizable are the results of large randomized controlled trials of antiretroviral therapy? HIV Med. 2000;1(3):149-154. doi:10.1046/j.1468-1293.2000.00019

23. Gwadz MV, Colon P, Ritchie AS, et al. Increasing and supporting the participation of persons of color living with HIV/AIDS in AIDS clinical trials. Curr HIV/AIDS Rep.

\section{ACKNOWLEDGEMENTS}

Statistical analyses and medical services were provided by Zatum LLC.

\section{CONFLICTS OF INTEREST}

The authors have each completed and submitted an ICMJE form for disclosure of potential conflicts of interest. The authors declare that they have no competing interests, financial or otherwise, related to the current work. E. Castellanos and B. Allan report personal fees from ViiV Healthcare during the conduct of the study, and personal fees from ViiV Healthcare outside the submitted work. N. Van de Velde reports other grants from ViiV Healthcare and GlaxoSmithKline outside the submitted work. G. M. Corbelli reports personal fees from ViiV Healthcare during the conduct of the study, and personal fees from ViiV Healthcare and HIV Vaccine Trials Network outside the submitted work. W.D. Hardy reports personal fees from ViiV Healthcare, during the conduct of the study; personal fees from ViiV Healthcare, personal fees from Advisory Boards, personal fees from Merck, personal fees from Gilead Sciences,
2010;7(4):194-200. doi:10.1007/s11904-010-0055-3

24. Okoli C, de Los Rios P, Eremin A, Brough G, Young B, Short D. Relationship Between Polypharmacy and Quality of Life Among People in 24 Countries Living With HIV. Prev Chronic Dis. 2020;17:E22. doi:10.5888/pcd17.190359

25. Hideo A, James F. An R package and tutorial for case 2 bestworst scaling. Journal of Choice Modelling. 2019;32:100171. doi:10.1016/j.jocm.2019.100171

26. DisplayR. MaxDiff Analysis Case Study Using R. https://docs. displayr.com/wiki/MaxDiff_Analysis_Case_Study_Using_R. Accessed April 10, 2020.

27. de los Rios P, Okoli C, Punekar Y, et al. Prevalence, determinants, and impact of suboptimal adherence to HIV medication in 25 countries. Prev Med. 2020;139:106182. doi:10.1016/j.ypmed.2020.106182

28. Sirur R, Richardson J, Wishart L, Hanna S. The role of theory in increasing adherence to prescribed practice. Physiother Can. 2009;61(2):68-77. doi:10.3138/physio.61.2.68

29. Jordan J, Cahn P, Goebel F, Matheron S, Bradley C, Woodcock A. Abacavir compared to protease inhibitors as part of HAART regimens for treatment of HIV infection: patient satisfaction and implications for adherence. AIDS Patient Care STDS. 2005;19(1):9-18. doi:10.1089/apc.2005.19.9

30. Delestras S, Roustit M, Mazet R, et al. Patient satisfaction with medication as an outcome for clinical pharmacists. International Journal of Clinical Pharmacy. 2005;19(1):9-18.

31. Ventura Cerda JM, Martin Conde MT, Morillo Verdugo R, Tebenes Cortes M, Casado Gomez MA. [Adherence, satisfaction and health-related quality of life in HIV-infected patients with antiretroviral therapy in Spain. The ARPAS study]. Farmacia Hospitalaria. 2014;38(4):291-299.

32. Boretzki J, Wolf E, Wiese C, et al. Highly specific reasons for nonadherence to antiretroviral therapy: results from the German adherence study. Patient Prefer Adherence. 2017;11:1897-1906. doi:10.2147/ppa.s141762

outside the submitted work. P. de los Rios and B. Young report other grants from ViiV Healthcare during the conduct of the study, as well as outside the submitted work. A. Eremin and C. Okoli report personal fees from ViiV Healthcare, during the conduct of the study. P. de los Rios, C. Okoli, B. Young, and N. Van de Velde are employees of ViiV Healthcare.

FUNDING

This work was supported by ViiV Healthcare.

\section{AUTHORS' CONTRIBUTIONS}

PD, CO, BY and NV conceptualized the study. All authors contributed to study design, analyses, drafting of the manuscript, and substantial revisions. All authors gave final approval for the manuscript to be submitted.

PROVENANCE AND PEER REVIEW

Not commissioned; externally peer reviewed. 